\title{
THE INNOVATIVE APPROACHES TO PACKAGING - COMPARISON ANALYSIS OF INTELLIGENT AND ACTIVE PACKAGING PERCEPTIONS IN SLOVAKIA
}

\author{
Erika Loucanova \\ Technical University in Zvolen, The Faculty of Wood Sciences and Technologies, \\ Department of Marketing, Trade and World Forestry, Slovak Republic \\ loucanova@tuzvo.sk \\ Martina Kalamarova \\ Technical University in Zvolen, The Faculty of Wood Sciences and Technologies, \\ Department of Marketing, Trade and World Forestry, Slovak Republic \\ martina.kalamarova@tuzvo.sk \\ Jan Parobek \\ Technical University in Zvolen, The Faculty of Wood Sciences and Technologies, \\ Department of Marketing, Trade and World Forestry, Slovak Republic \\ parobek@tuzvo.sk
}

(Received January 2017; Accepted April 2017)

\begin{abstract}
Packaging has always served a practical function - to hold goods together and protect it when moving toward the customer through distribution channel. Today packaging is also a container for promoting the product and making it easier and safer to use. The sheer importance of packaging functions is still growing and consequently the interest of the company is to access to the packaging more innovative and creative. The paper deals with the innovative approaches to packaging resulting in the creation of packaging with interactive active features in the form of active and intelligent packaging. Using comparative analysis, we monitored the perception of the active packaging functions in comparison to intelligent packaging function among different age categories. We identified the age categories which are most interested in these functions.
\end{abstract}

Key words: innovation, active packaging, intelligent packaging, functions of packaging.

\section{J.E.L. CODES: O31, 032}

\section{Introduction}

The importance of the packaging system and its various functions is increasing over the last decades. In traditional terms, the packaging is intended as a means of protection, preservation, handling, transport and storage of products. Nowadays, the other functions of packaging, such as promotion, getting the attention of customers and brand communication are becoming more recognizable. As a result, the current interest of the company is therefore to offer a customer such a packaging that will meet the marketing requirements and the needs of handling and transport at the same time. In the case of innovation it is important to target it to the 
Loucanova E., Kalamarova M., Parobek J. (2017)

The innovative approaches to packaging - comparison analysis of intelligent and active packaging perceptions in Slovakia

specific customer segment and therewith it is in the company's interest to properly identify the target groups of the packaging innovation. According to this the aim of the paper is to identify the age categories which are most interested in packaging innovation and to monitor the perception of the active packaging functions in comparison to intelligent packaging function among different age categories.

\section{Literature Review}

The packaging is one of the most important parts forming the product. Its size, shape, design, selected color and font significantly influence the consumer decision-making process and thereby affect the marketability of the product itself (Kotler, 2001).

When creating product innovations it is necessary to think about the product at different levels whereas each level increases its value to the customer (Zauskova, 2016). Regarding the packaging innovation it is necessary to monitor packaging functions and find out if it can be used also for another function than just the primary ones as security, handling and information function. Companies should monitor changes in consumers' preferences and also focus on the attention to the new technology of packaging when selecting and introducing the packaging to the market.

In the past, there was a change in design about every 15 years, but now due to the changes in the market environment and the impact of environmental pressure the companies should apply more innovative and creative approach to packaging. Therefore the function facilitating recycling and reducing environment damage is becoming increasingly important to the main packaging functions such as contain and protect products, promote products, and facilitate the storage, use and convenience of product.

Traditional perception of packaging classifies the main functions of packaging into four basic categories: protection, communication, convenience and containment (Paine 1991, Robertson, 1993 In Yam et al. 2005), nevertheless, these functions are not totally exclusive - for example, the communication function of the package can also help to enhance food protection and convenience. The package is used to (Yam et al., 2005):

- protect the product against the deteriorative effects of the external environment,

- communicate with the consumer as a marketing tool,

- provide the consumer with greater ease of use and time-saving convenience,

- contain products of various sizes and shapes.

Based on the literature review, currently, different authors deal with several ways of the packaging functions classification. For example, Zeman (2005) and Kacenak 
Loucanova E., Kalamarova M., Parobek J. (2017)

The innovative approaches to packaging - comparison analysis of intelligent and active packaging perceptions in Slovakia

(2001) referred to 6 key function classifications: protection, guarantee, rationalization, economic, communication and ecological. Dzurova (1997) refers to the classification according to Schulte, who lists five functions, namely: protection, storage, transport, handling and information. According to Kollar (1999) essential functions are the protection, handling, information and publicity, environmental and economic.

Innovative packaging is the result of creative, unconventional thinking outside the usual framework of thought (Yam et al., 2005). The result of an innovative approach to packaging is the creation of packaging with interactive features. Actually two groups of such packaging systems are distinguished: intelligent and active packaging. They focus to improve packaging functions to meet current consumer demands, increased regulatory requirements, as well as increased interest in security (Fig. 1).

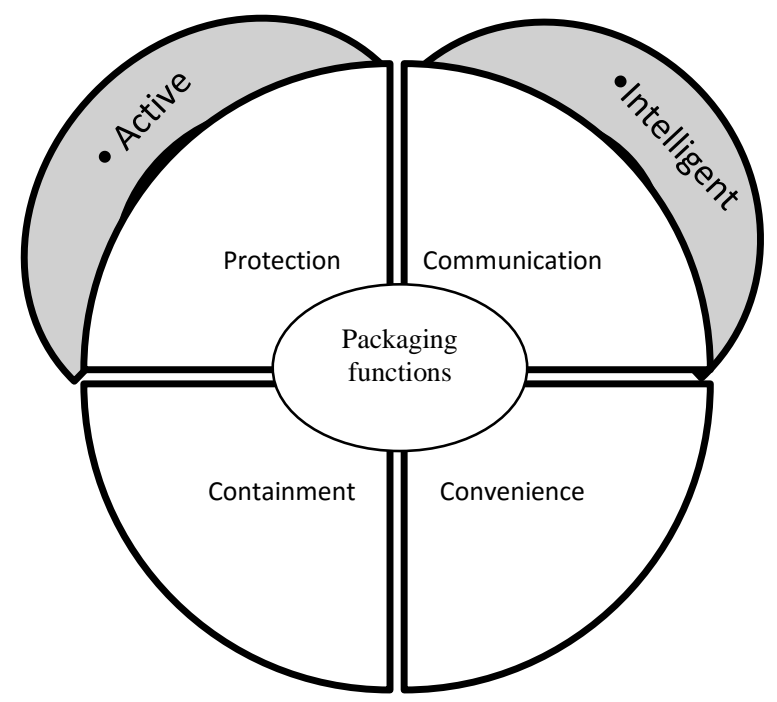

Figure 1 Model of packaging functions

Source: Yam a et al. (2005)

Active packaging represents shifts in the perception of functions, namely, the protection function of packaging has been shifted from passive to active. In the traditional perception, the protection function of the package meant a passive barrier between the product and its environment. Regarding active packaging the aim of protective function is to actively protect the product (Yam et al. 2005). 
Loucanova E., Kalamarova M., Parobek J. (2017)

The innovative approaches to packaging - comparison analysis of intelligent and active packaging perceptions in Slovakia

Active packaging allows actively changing the condition of the package to extend shelf life or improve food safety, while maintaining the quality of the food (Kacenak, 2011). Following the definition of active packaging materials, we can group them according to the way in which they affect the characteristics of the product as follows: absorbers - active packaging systems based on absorption and emitters - active packaging systems based on the release of substances (Sosnovcova, 2008).

Intelligent packaging is a packaging system that is capable of carrying out intelligent functions (such as detecting, sensing, recording, tracing, communicating, and applying scientific logic) to facilitate decision making to extend shelf life, enhance safety, improve quality, provide information, and warn about possible problems (Yam et al., 2005). According to Kacenak (2011) intelligent packaging is the term for systems that monitor conditions around the product and thus provide information about the quality of food during transport and storage. The time-temperature indicators, indicators of oxygen and carbon dioxide, the color temperature indicators, pathogen indicators and breakage indicators are distinguished (Sosnovcova, 2008).

Following the literature review the importance of active and intelligent packaging means mainly significant expansion of two packaging functions: protective function - especially in active packaging shift from passive to active protection and information functions - especially as intelligent packaging providing information monitoring the packing conditions. According to Loucanova et al (2016) the requirements of customers to the innovation of packaging functions are as follows: the majority of respondents expect the packaging to be ecological and to fulfill mainly the information and protection function. These results confirm the actuality of intelligent and active packaging in terms of required packaging functions and therefore innovative packaging thus respond to the current market requirements.

The companies should orientate mainly to these functions and innovate the packaging to be easily biodegradable in the nature, produced from friendly, recyclable materials, ensuring high degree of protection of the products as well as consumers. Potential customers are demanding more and more information of product composition, quality, date mark and durability, thereby the companies should respond by that kind of innovation to meet these requirements. Regarding that research (Loucanova et al, 2016) the target group for packaging innovation represents the age category from 41 to 50 years according to their highest innovation status. This age category recognizes its own requirements in purchasing and selecting products and it considers protection and information function as the main important and ecological function as attractive. 
The innovative approaches to packaging - comparison analysis of intelligent and active packaging perceptions in Slovakia

\section{Methodology}

The principal method of the research for the perception of packaging innovations in terms of the functions is a method of the Kano model. The aim of the Kano model is to capture customers' opinion according to the requirements of an observed object (Goodpasture, 2003). The methodology consisted of several steps:

$>$ compiling questionnaire to individual functions of packaging innovations,

$>$ questionnaire measures for gathering specifiable information,

$>$ evaluation,

$>$ processing the results in a matrix of typology of perception of packaging innovations in terms of the functions by respondents and subsequent interpretation.

KANO questionnaire is compiled based on the monitored parameters, in this case packaging functions - protection, communication, convenience and containment. The questionnaire consisted of pairs of positively and negatively conceived statements regarding the performance of these packaging functions. According to the methodological approach respondents had an opportunity to respond every question (statement) on a scale from 1 to 5 representing strong agreement to strong disagreement with that question (statement) based on the draft. The sample of respondents was set at 120 respondents in Slovakia, keeping the same proportion of respondents for each given age category. The survey was conducted through electronic forms and personal questioning.

In the following analyses, received responses are evaluated according to the cross rule (Table 1).

Table 1 The Kano Model

\begin{tabular}{|c|l|c|c|c|c|c|c|}
\hline \multicolumn{2}{|c|}{} & \multicolumn{5}{|c|}{ Answer to the Dysfunctional Question } \\
\cline { 3 - 8 } \multicolumn{2}{|c|}{} & Like & Acceptable & $\begin{array}{c}\text { No } \\
\text { Feeling }\end{array}$ & Must-be & $\begin{array}{c}\text { Do not } \\
\text { like }\end{array}$ & Other \\
\hline \multirow{4}{*}{$\begin{array}{c}\text { Answer to } \\
\text { the } \\
\text { Functional } \\
\text { Question }\end{array}$} & Like & S & A & A & A & O & \\
\cline { 2 - 8 } & Acceptable & R & I & I & I & M \\
\cline { 2 - 8 } & No Feeling & R & I & I & I & M \\
\cline { 2 - 8 } & Must-be & R & I & I & I & M \\
\cline { 2 - 7 } & Do not like & R & R & R & R & S \\
\cline { 2 - 7 } & Other & \multicolumn{6}{|c|}{ "Other" responses are ignored } \\
\hline
\end{tabular}

Source: Grapentine, 2015

The responses are subsequently evaluated by two-factor analysis based on age categories. Based on the Kano model, the findings were included in the following categories according to how respondents perceived new packaging: 
Loucanova E., Kalamarova M., Parobek J. (2017)

The innovative approaches to packaging - comparison analysis of intelligent and active packaging perceptions in Slovakia

$>\mathrm{M}$ (must be requirements) - are obligatory requirements that customers consider as normal and are automatically expected. These requirements can be identified as primary or basic and therefore, they only deal with customers in the event of non-compliance. Identifying them is of elementary importance mainly because even though their fulfillment is reflected in customers' satisfaction, their deficit and failure is reflected in customers' dissatisfaction as they immediately realize it.

$>\mathrm{O}$ (one-dimensional requirements) - that are represented by those product attributes that lead to fulfillment and satisfaction in the event of noncompliance to customers dissatisfaction, i.e., the higher the degree of compliance with these requirements, the more satisfied the customers are, but compared to the mandatory requirements customers automatically do not expect them.

$>\mathrm{A}$ (attractive requirements) - that have a clear impact on customers satisfaction because it is a requirement that customers did not expect.

$>\mathrm{R}$ (reverse requirements) - are contradictory, they bother customers, as they require some additional action from them.

$>$ I (indifferent requirements) - are requirements which do not have any influence on customers. They are also called irrelevant requirements. This category involves the attributes that are not critical for customers and their pass or fail does not affect their satisfaction or dissatisfaction (Ducar et al. 2006).

$>\mathrm{S}-$ are skeptical, questionable requirements (Grapentine, 2015; Loucanova et al. 2016).

The results of Kano model allowed us to divide the monitored packaging functions into categories of mandatory, attractive, indifferent and reverse functions.

Subsequently, the comparison analysis, which aims to identify and measure comparable data, was used. It was used to identify the differences between customers' perceptions of intelligent packaging functions and customers' perceptions of active packaging functions. According to packaging functions definition by Yam et al. (2005) we considered expansion of protection and containment function as a nature of active packaging and the expansion of communication and convenience function as a nature of intelligent packaging.

The comparison analysis was based on the customer requirements identification by Kano model. In the next step the weight were assigned to these requirements. Every identified requirement represents value 1, which was multiplied by weight according to identified category as follows: must be $=3$, attractive $=2$, onedimensional $=1$, indifferent $=0$, reverse $=-1$ (Loucanova, 2015). Based on the sum of values, we can compare customers' perceptions of active and intelligent 
Loucanova E., Kalamarova M., Parobek J. (2017)

The innovative approaches to packaging - comparison analysis of intelligent and active packaging perceptions in Slovakia

packaging functions and we identify the target age group for active and intelligent packaging.

\section{Result and discussion}

The survey results indicate different attitudes to intelligent and active packaging according to age. The Kano model identified requirements of the packaging functions among the monitored age categories. The customer's value (table 2) was calculated as the sum of the points that have been assigned to the individual categories of the questionnaire, according to the methodology.

Table 2 The comparison analysis of perceptions of intelligent and active packaging functions in Slovakia

\begin{tabular}{|c|c|c|c|c|c|c|}
\hline & \multicolumn{5}{|c|}{ Packaging functions } \\
\hline & & Containment & Protection & Communication & Convenience & Total \\
\hline \multirow{3}{*}{$18-30$} & Requirement & $\mathrm{I}$ & I & I & $\mathrm{O}$ & - \\
\hline & AP function & 0 & 0 & - & - & 0 \\
\hline & IP function & - & - & 0 & 1 & 1 \\
\hline \multirow{3}{*}{$31-40$} & Requirement & $\mathrm{R}$ & $\mathrm{O}$ & I & $\mathrm{O}$ & - \\
\hline & AP function & -1 & 1 & - & - & 0 \\
\hline & IP function & - & - & 0 & 1 & 1 \\
\hline \multirow{3}{*}{$41-50$} & Requirement & A & $\mathrm{O}$ & $\mathrm{O}$ & A & - \\
\hline & AP function & 2 & 1 & - & - & 3 \\
\hline & IP function & - & - & 1 & 2 & 3 \\
\hline \multirow{3}{*}{$51-60$} & Requirement & $\mathrm{O}$ & $\mathrm{O}$ & $\mathrm{O}$ & $\mathrm{O}$ & - \\
\hline & AP function & 1 & 1 & - & - & 2 \\
\hline & IP function & - & - & 1 & 1 & 2 \\
\hline \multirow{3}{*}{$61+$} & Requirement & A & I & I & I & - \\
\hline & AP function & 2 & 0 & - & - & 2 \\
\hline & IP function & - & - & 0 & 0 & 0 \\
\hline
\end{tabular}

Notes: AP - Active packaging, IP - Intelligent packaging

Source: authors' computation

The results indicate that the most significant value from the perspective of active and intelligent packaging functions is for customers' age category 41 to 50 , followed by age categories 51 to 60 and older.

Active packaging has value mostly for the customers in the age of 41 and older, for whom the active packaging represents an attractive and one-dimensional requirement. It represents those active packaging attributes that lead to fulfillment and satisfaction in the event of non-compliance to customers' dissatisfaction. The higher the degree of compliance with these requirements, the more satisfied the 
Loucanova E., Kalamarova M., Parobek J. (2017)

The innovative approaches to packaging - comparison analysis of intelligent and active packaging perceptions in Slovakia

customers are and in addition, the attractive requirements have a clear impact on customers satisfaction increase. The younger ones (less than 40 years) are not affected by active packaging and their functions. The functions are indifferent for them, it involves the attributes that are not critical for customers and their pass or fail does not affect their satisfaction or dissatisfaction, figure 2 .

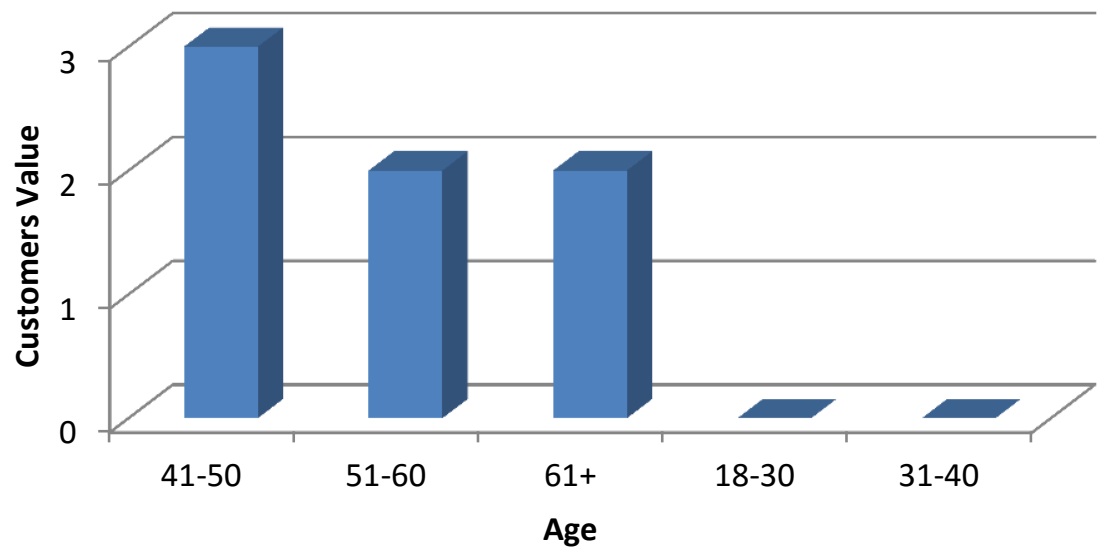

Figure 2 The customer value of active packaging functions

Source: authors' computation

Regarding intelligent packaging the most influenced group is age category 41 to 50 , followed by 51 to 60 and then with the same value 18 to 30 and 31 to 40 . Basically the intelligent packaging influences the customers in the age 18 to 60 very similarly: they represent one-dimensional requirement - the higher the degree of compliance with these requirements, the more satisfied customers are. The age category 61 and older does not react to intelligent packaging, they are indifferent to them, figure 3.

The comparison of the value of active and intelligent packaging functions for the customers indicates the differences in target groups of customer affected by these functions, figure 4. The respondents in younger age are more oriented to the intelligent packaging. The generation of middle-aged is interested in intelligent and also in active packaging equally. And finally the older age categories rather prefer only active packaging. 


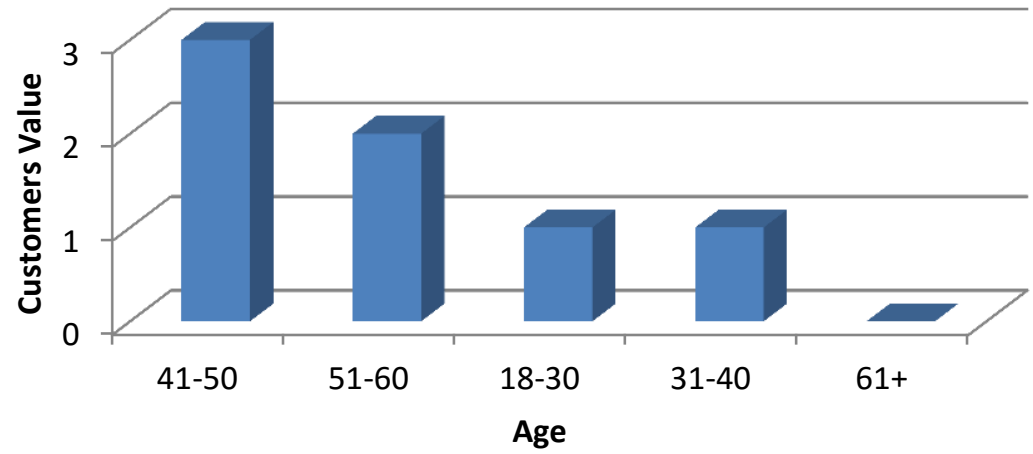

Figure 3 The customer value of intelligent packaging functions Source: authors' computation

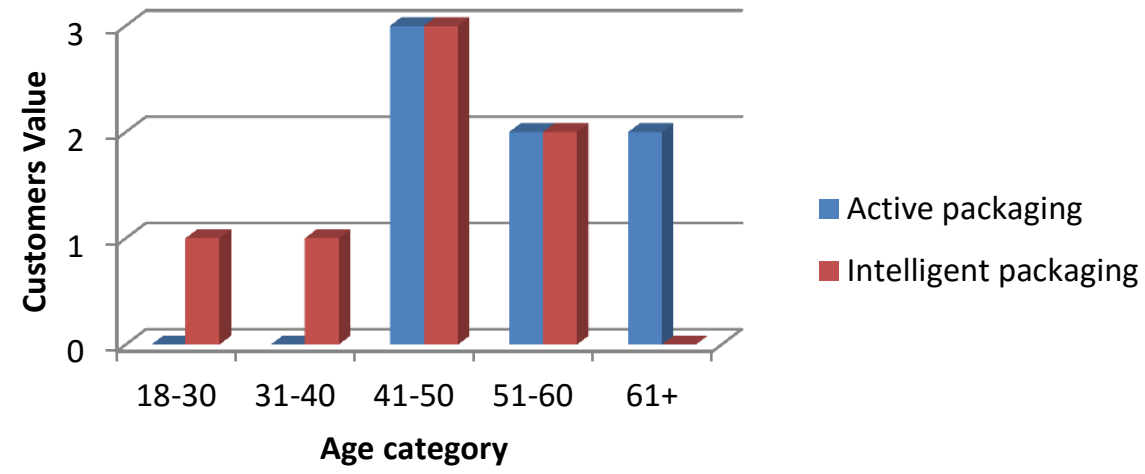

Figure 4 The comparison of the value of active and intelligent packaging functions for

Source: authors' computation the customers

Active and intelligent packaging influence customer decisions mainly as onedimensional requirement, i.e. those active packaging attributes that lead to fulfillment and satisfaction and in the event of non-compliance to customers dissatisfaction - the higher the degree of compliance with these requirements, the more satisfied customers are. Occasionally they can be perceive as attractive requirements for the customers that have a clear and significantly increasing impact on customers satisfaction because it is a requirement that customers did not 
According to the innovative approaches to the packaging can be concluded that younger respondents are more focused on the intelligent functions of the packaging. That one according to Yam et al. (2005) are able to perform intelligent functions to facilitate decision-making, enhance safety, improve quality, provide information and warn of potential problems, causing the mental shortcuts to facilitate cognitive processes in decision-making (Helus, 2015). These respondents decide according to the first impression caused by the innovation, which is closely connected to the communication function of the package evolving especially by intelligent packaging.

As age increases, the older generation emphasizes active protection of the product and appreciates easy-handling. Exactly active packaging focuses on protection and containment, representing a shift from passive to active perception of packaging. In case of interest to reach customers by active packaging the focus should be on the elderly.

\section{Conclusion}

The sheer importance of packaging functions is still growing and consequently the interest of the company is to access the packaging in a more innovative and creative way. The results of the Kano model and comparative analysis indicate that the main target group for the active and intelligent packaging is consumers of age category from 41 to 50 years. They have the highest requirements for packaging innovation given the highly innovative status. With increasing age of the target age group customers are more oriented on active packaging functions and contrary to intelligent packaging functions with decreasing age. Therefore, we suggest innovators lead innovation of active and intelligent packaging towards age, type of product and its functions according to the findings of the paper. In addition to the above-mentioned facts, the paper has theoretical as well as practical benefits in the form of recommendations for innovators in regards of active and intelligent packaging. This can then be reflected in the performance of companies and their investment decisions as stated Loucanova (2016); Ipate et al. (2015); Baltes, et al. (2014), Straka (2013), Stofkova (2013) and Borlea et al. (2016).

\section{Acknowledgement}

The authors would like to thank the European Cooperation in the field of Scientific and Technical Research - COST. This paper was elaborated within the frame of COST Action FP1405 "Active and Intelligent Fibre-Based Packaging - Innovation and Market Introduction (ACTINPAK)" and Grant project 1/0756/16 "Identification of consumers' segments according to their affinity for 
Loucanova E., Kalamarova M., Parobek J. (2017)

The innovative approaches to packaging - comparison analysis of intelligent and active packaging perceptions in Slovakia

environmental marketing strategies of business entities in Slovakia". The authors therefore would like to thank the Scientific Grant Agency of the Ministry of Education, Science, Research and Sport of the Slovak Republic and the Slovak Academy of Sciences, too.

\section{References}

1. Baltes, N., Dragoe,A., G., M., Adelean, D. I. (2014) Study regarding the determination of the financial performance of a company through market rates, Studia Universitatis "Vasile Goldis" Arad Economics Series, 24(3).

2. Borlea, S, N., Mare, C., Achim, M. V., Puscas, A. (2016) Direction of causality between financial development and economic growth. Evidence for developing countries, Studia Universitatis "Vasile Goldis" Arad Economics Series, 26(2)

3. Calver, G. (2004). What is packaging design? RotoVision, 2004. 255 p. ISBN 978-288046-618-0.

4. Ducar S., Nascakova J., Malak M. (2006). Navrh systemu merania spokojnosti zakaznikov Kano modelom. Transfer inovacii 9/2006. s. 137-139. ISBN 80-7093-6.

5. Dzurova, M. (1997). Obal a balenie ako sucast' logistiky. Bratislava: Eurounion, 1997. 144 s. ISBN 80-85568-80-2.

6. Goodpasture, J. (2003). Quantitative Methods in Project management. USA: J. Ross Publishing, 2003. 288 s. ISBN 1-932159-15-0.

7. Grapentine, T. (2015). Why the Kano model wears no clothes. Quirks Marketing Research Media, 34/2015. (online) http://www.quirks.com/articles/2015/20150407.aspx

8. Helus, Z. (2015). Socialni psychologie pro pedagogy. Praha: Grada, 2015. 400 s. ISBN 978-80-247-4674-6.

9. Ipate, N., David, K. G., Ipate, I., Bogdan, A. (2015). The bioeconomy model in future sustainable development, Studia Universitatis "Vasile Goldis" Arad Economics Series 25, $2 / 2015$.

10. Kacenak, I. (2011). Trendy rozvoja potravinarskej obalovej techniky. Bratislava: Vydavatel'stvo EKONÓM, 2011. ISBN 978-80-225-3326-3.

11. Kollar, V. (1999). System a specifikacia produktovej politiky. Bratislava: Sprint, 1999, ISBN 80-888848-05-9.

12. Kotler, P. (2001) Marketing magement. Praha: Grada Publishing, 2001. 720 s., ISBN 80-247-0016-6.

13. Loucanova, E. (2015) Navrh metodiky nastrojov pre efektivne riadenie inovacii na zaklade poziadaviek zakaznikov, Posterus, 8, 4/2015, ISSN 1338-0087.

14. Loucanova, E. (2016) Inovacne analyzy a strategie. Zvolen: Technicka univerzita vo Zvolene, 2016. 149 s. ISBN 978-80-228-2899-4.

15. Loucanova, E., Parobek, J., Kalamarova, M. (2016). The perception of respondents of packaging innovations in Slovakia. Studia Universitatis "Vasile Goldis" Arad - Economics Series, 26, 3/2016.

16. Regattieri, A., Santarelli, S. (2013). The Important Role of Packaging in Operations Management, Operations Management, 3/2013. 
Loucanova E., Kalamarova M., Parobek J. (2017)

The innovative approaches to packaging - comparison analysis of intelligent and active packaging perceptions in Slovakia

17. Sosnovcova, J. (2008) Aktivni a inteligentni obalove systemy pro baleni potravin, Vedecky vybor pro potraviny, Brno: 2008.

18. Stofkova, K. (2013). Sietove podnikanie. Manazment a sietove podnikanie vo vedomostnej ekonomike. Zilina: Zilinska univerzita, 2013, ISBN 978-80-554-0804-0, s. 2560.

19. Straka M. (2013): Logistika distribucie, Ako efektivne dostat' vyrobok na trh, Bratislava, EPOS 2013, 400 s., ISBN 978-80-562-0015-5.

20. Yam, K.L., Takhistov, P.T., Miltz, J. (2005). Intelligent Packaging: Concepts and Applications, Journal of Food Science, vol. 70, no. 1, 2005.

21.Zeman, S. (2005). Balenie a obalova technika. Nitra: Slovenska polnohospodarska univerzita, 2005. 177 s. ISBN 80-8069-634-9. 